\title{
Stabilization of Deep Excavation in Loose Fill Using Soil Nail Wall
}

\author{
E. Ebrahimnezhad Sadigh, M. A. Mojtahedi \\ Larzeh Sakht Savalan, Consulting Engineers Co. \\ No.7, 6th 6m, 1st East 18 m St., Zafaranieh, Tabriz, Iran \\ info@larzehsakht.com
}

\begin{abstract}
In recent years, due to city development, excavation and building construction in the loose fill of the south side of Tabriz, Iran is inevitable. This paper presents a case study of stabilization of a $16 \mathrm{~m}$ deep excavation in loose fill using soil nail wall in the south of Tabriz. Design, construction, construction difficulties and their solutions are discussed in this paper. The finite element analysis is conducted. The numerical simulation of soil nail wall is verified via comparing calculated wall displacement with the field measured values. The results show that in the sites without sensitive structures to deform in the vicinity of the excavation area, soil nailing is an effective and economical method for stabilization of excavations with a vertical cut in the loose fill. For better matching of calculated displacements of soil nail wall with field measured values, using hardening soil model and simulation of construction stages according to the actual execution in the site is recommended.
\end{abstract}

Keywords: Soil nail wall, Loose fill, Finite element, Loose granular soil, Excavation, Stabilization, Field measurement

\section{Introduction}

Since early $81 \mathrm{~s}$, earthworks due to increasing of urban construction in Tabriz have caused the filling of valleys located at south edge of city and vast regions of loose fill have been created. In recent years, in order to develop the city, excavation and building construction is inevitable in these regions.

Soil nailing is an effective method for stabilization of excavation with the vertical cut in urban areas. The main advantages of soil nail walls included enough working space in front of excavation face, requiring light machinery and equipment for construction, rapid construction, flexibility and compatibility with large total and differential settlement, appropriate performance during seismic events, deflections within tolerable limits and finally they are economical than conventional concrete gravity walls and ground anchor walls [1].

This paper presents a case study of stabilization of $16 \mathrm{~m}$ deep excavation with the vertical cut in loose granular soil. In addition, Design, construction, construction difficulties and their solutions are discussed. The finite element analysis using the computer program Plaxis is conducted. The calculated displacement of soil nail wall is compared with field-measured values to verify the finite element model.

\section{Project overview and geotechnical condition}

This case study comprises a residential building with 4-story basement. The excavated area was $957 \mathrm{~m}^{2}$ and the depth of excavation was $16 \mathrm{~m}$. Geotechnical conditions based on subsurface investigation are as follows:

- The upper deposit consists of loose fill. The fill material includes silty sand. Figure 1 shows the contour curves of loose fill depth in the excavation area. Minimum depth of loose fill is $8 \mathrm{~m}$ at the northeast corner and the maximum depth is $15 \mathrm{~m}$ at northwest side.

- The lower deposit consists of alternatively cemented silty sand and sandy siltstone. This layer is overlaid by loose fill.

The excavation area is surrounded by a street on the north side, one-story building on the east side and alley on the south and west side. In this paper, soil nail wall of the west side is studied. The Average depth of loose fill on the west side of excavation is $13 \mathrm{~m}$. Figure 2 shows the variation of loose fill depth at excavation section of the west side. 


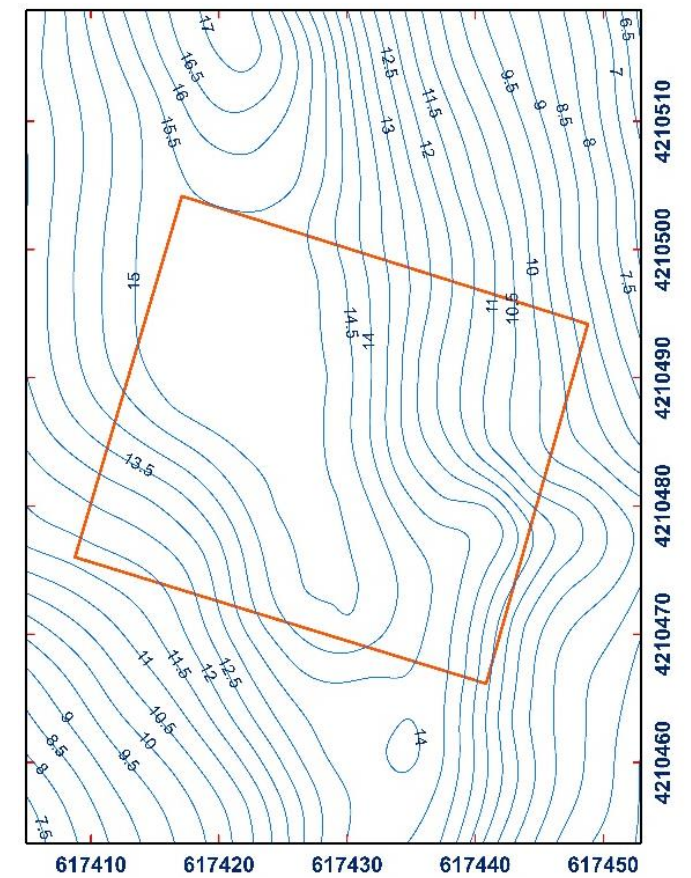

Fig. 1: Contour curves of loose fill depth in the excavation area.

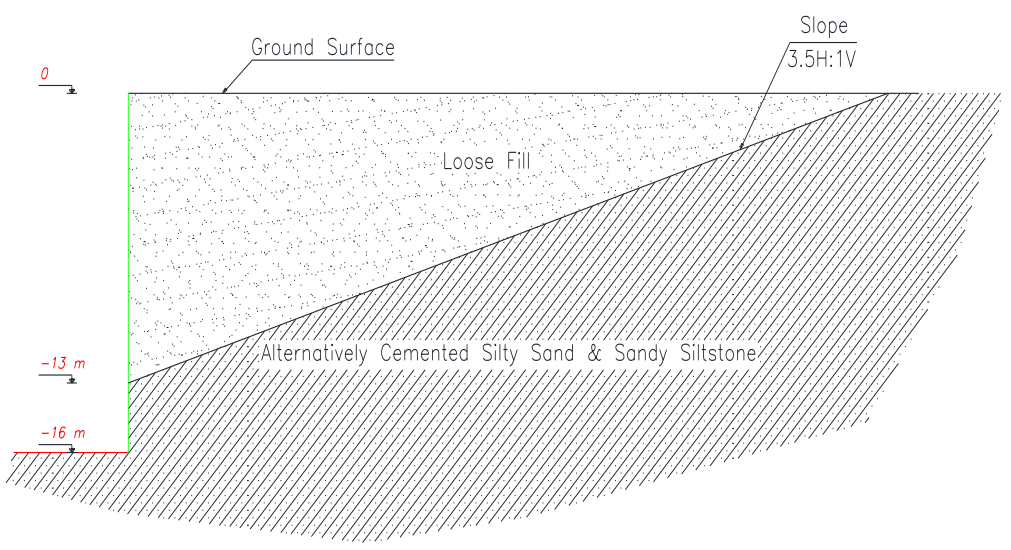

Fig. 2: Excavation section in west side.

\section{Soil nail wall design and construction}

\subsection{Design}

The design of soil nail wall was carried out in accordance with the allowable stress design procedure [1]. In this procedure, length, vertical and horizontal spacing of nails, nail inclination, the diameter of nail bar and drill hole are obtained from limit equilibrium stability analysis. Soil nail wall geometric configuration is summarized in Table 1. Figure 3 shows the section of soil nail wall. 
Table 1: Soil nail wall geometry configuration.

\begin{tabular}{ll}
\hline Parameter & Value \\
\hline Height of the wall $\mathrm{H}(\mathrm{m})$ & 16 \\
Face batter $\alpha(\mathrm{deg})$ & 0 \\
Backslope angle $\beta(\mathrm{deg})$ & 0 \\
Diameter of nail bar $(\mathrm{mm})$ & 32 \\
Drill hole diameter $\mathrm{D}_{\mathrm{DH}}(\mathrm{mm})$ & 120 \\
Length of nail $\mathrm{L}(\mathrm{m})$ & $7,14,12$ \\
Vertical spacing of nails $\mathrm{S}_{\mathrm{v}}(\mathrm{m})$ & $1.5,1.4$ \\
Horizontal spacing of nails $\mathrm{S}_{\mathrm{h}}(\mathrm{m})$ & 1.4 \\
Nail inclination $(\mathrm{deg})$ & 15 \\
\hline
\end{tabular}

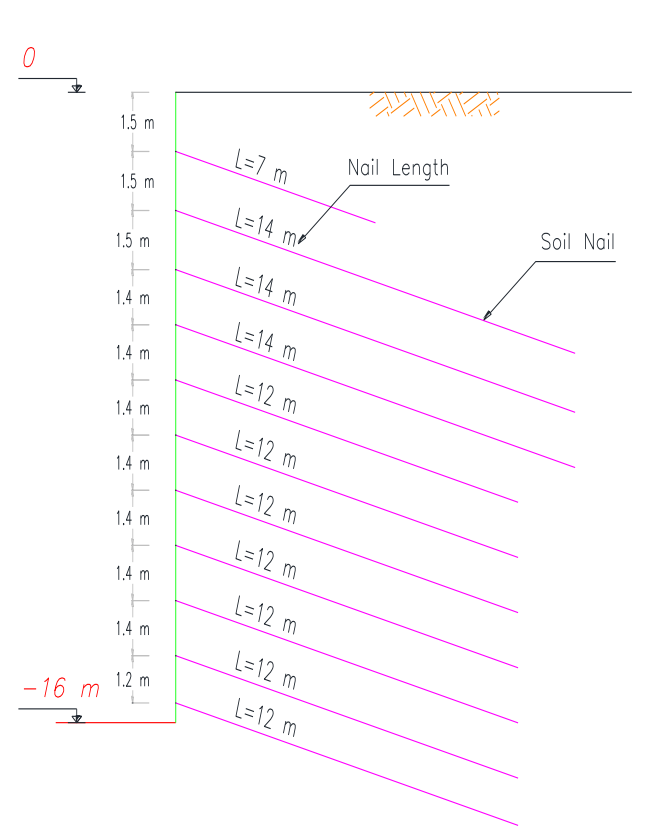

Fig. 3: Section of soil nail wall.

\subsection{Construction}

The construction of the soil nail wall was carried out in a top-down sequence. Due to high collapsibility of the loose fill, the excavation face was not able to remain unsupported before nail and facing installation for depth more than $0.7 \mathrm{~m}$. In each level, the drill hole was drilled by rotary method. Centralizers were placed around the nail prior to insertion. The nail bar with grout pipe was inserted in the drill hole. Then, the drill hole was filled with grout in two steps. In the first step, the grout was placed under gravity without interruption and from bottom to top. In the second step, after closing the top of drill hole the grout is placed under pressure of 2-3 bar to ensure good grout-soil bonding. Then a shotcrete facing was constructed to support the open-cut soil section before the next lift of soil is excavated. The thickness of shotcrete based on design was $100 \mathrm{~mm}$ but in some lifts, the thickness was increased to $300 \mathrm{~mm}$ in order to prevent the collapse of excavation face. This sequence was repeated for other excavation lifts until the final excavation level (Figure 4). 


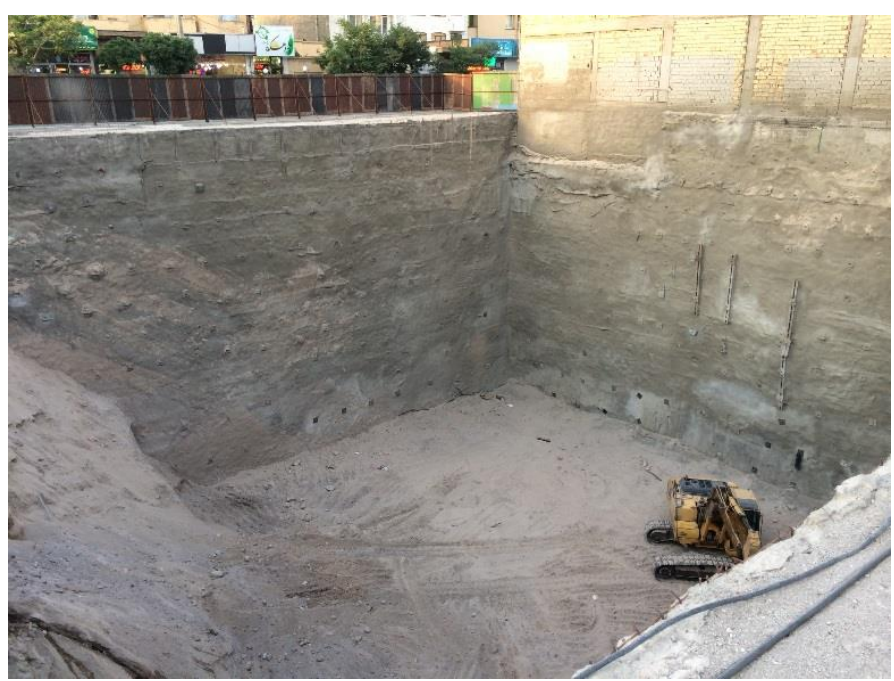

Fig. 4: The view of soil nail wall.

\section{Finite element analysis}

\subsection{Finite element modeling}

In this paper, for numerical modeling of soil nail wall finite element code Plaxis was used to simulate the excavation sequence and installation of nails [2], [3] and [4]. Figure 5 shows the finite element model of soil nail wall and its dimensions. Left and right boundary of the model were fixed in horizontal direction while the bottom boundary was fixed in all directions. The soil mass was simulated using triangle elements with 15 nodes. As the nail was slender, steel reinforcement with little bending rigidity, it was modeled using the geogrid element that was only capable of sustaining the axial force [5]. The shotcrete facing of wall was modeled using plate element. In this study, the Mohr-Coulomb Model (MC-model) and Hardening Soil Model (HS-model) were selected as the soil model and the results of each model were discussed [6]. Based on laboratory and in-situ tests, Soil parameters used for finite element analysis are summarized in Table 2.

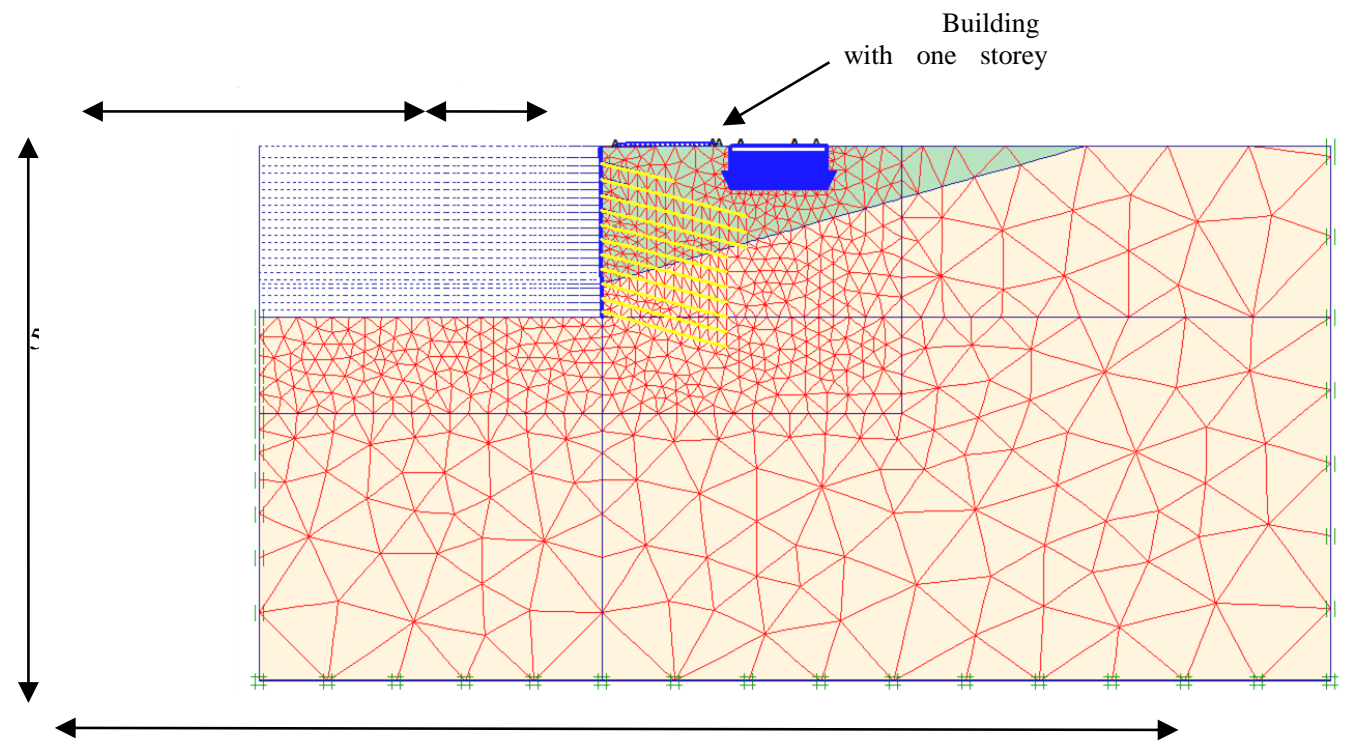

Fig. 5: Finite ellement model of soil nail wall. 
Table 2: Soil model parameters.

\begin{tabular}{lcccc}
\hline Soil Layer & \multicolumn{2}{c}{ Loose fill } & \multicolumn{2}{c}{$\begin{array}{c}\text { Alternatively cemented silty } \\
\text { sand and sandy siltstone }\end{array}$} \\
\hline Parameter & MC & HS & MC & HS \\
\hline Unit weight $g\left(\mathrm{kN} / \mathrm{m}^{3}\right)$ & 18 & 18 & 18 & 18 \\
Cohesion $c\left(\mathrm{kN} / \mathrm{m}^{2}\right)$ & 0 & 0 & 30 & 30 \\
Friction angle $\phi(\mathrm{deg})$ & 28 & 28 & 38 & 38 \\
Dilatancy angle $\psi(\mathrm{deg})$ & 0 & 0 & 8 & 8 \\
Modulus of elasticity of soil $E\left(\mathrm{kN} / \mathrm{m}^{2}\right)$ & 10,000 & - & 100,000 & - \\
Secant stiffness in standard drained triaxial test $E^{\text {ref }}{ }_{50}\left(\mathrm{kN} / \mathrm{m}^{2}\right)$ & - & 7,000 & - & 100,000 \\
Tangent stiffness for primary oedometer loading $E^{\text {ref }}{ }_{\text {oed }}\left(\mathrm{kNN} / \mathrm{m}^{2}\right)$ & - & 7,000 & - & 100,000 \\
Unloading/reloading stiffness $\mathrm{E}^{\text {ref }}{ }_{\mathrm{ur}}\left(\mathrm{kN} / \mathrm{m}^{2}\right)$ & - & 21,000 & - & 300,000 \\
Poisson's ratio $\vartheta$ & 0.3 & 0.2 & 0.3 & \\
\hline
\end{tabular}

Staged construction option in plaxis was used to simulate construction of soil nail wall. Two methods of simulation were used as follows:

- Common staged construction (CSC)

In this method according to the common simulation of soil nail wall construction in literature deactivating of soil cluster and activating of nail and facing elements were carried out simulataneously in one stage. The depth of excavation lifts is 1.4 to $1.5 \mathrm{~m}$. Figure 6 shows the excavation lifts in CSC method.

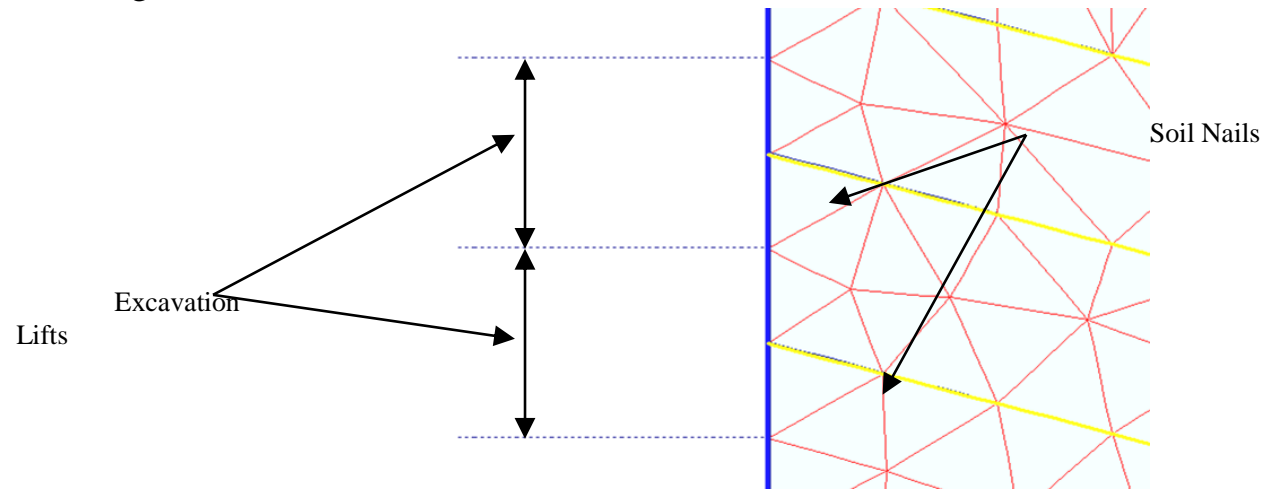

Fig. 6: Excavation lifts in common staged construction method.

- Actual staged construction (ASC)

In this method based on the actual stages of soil nail wall construction in site, deactivating of soil cluster and activating of nail and facing elements were carried out separately in two stages. Figure 7 shows the excavation lifts in ASC method. According to the construction of soil nail wall in site, excavation lifts were two types consist of excavation lift with nail (E1 , E3) and without nail (E2). The depth of all types of excavation lifts is 0.7 to $0.8 \mathrm{~m}$. Excavation lifts with nail element were simulated in two stages. In first stage, soil cluster was deactivated and facing was activated. In this stage, the deformation of excavation face before installation of nail was created. In second stage nail element was activated. Excavation lift without nail element (E2) was simulated in one stage. 


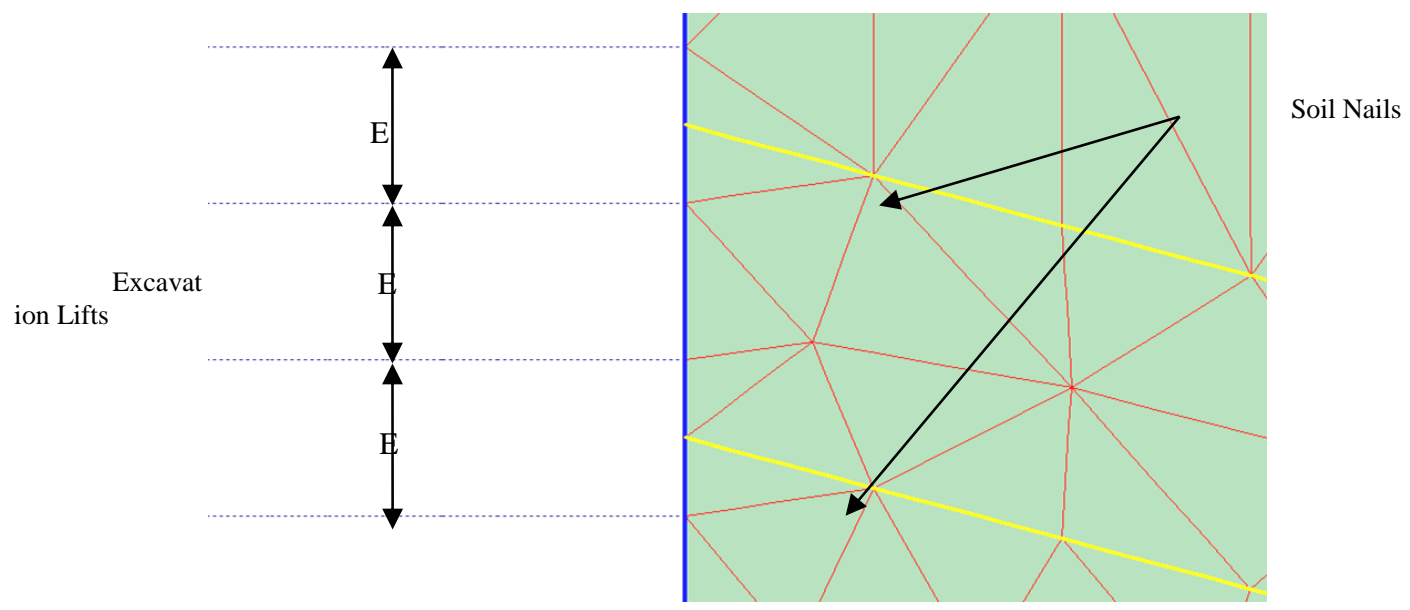

Fig.7: Excavation lifts in actual staged construction method.

\subsection{Analyses results}

The finite element results presented in this paper include maximum lateral displacement of soil nail wall which usually occurs at top. Figure 8 shows the maximum lateral displacement of soil nail wall with construction stage of wall based on field measured values and analyses results. The analyses are carried out for two types of soil model consist of MohrCoulomb model and Hardening-Soil model and two methods of construction simulation consist of CSC and ASC methods.

Maximum lateral wall displacement, $\mathrm{mm}$

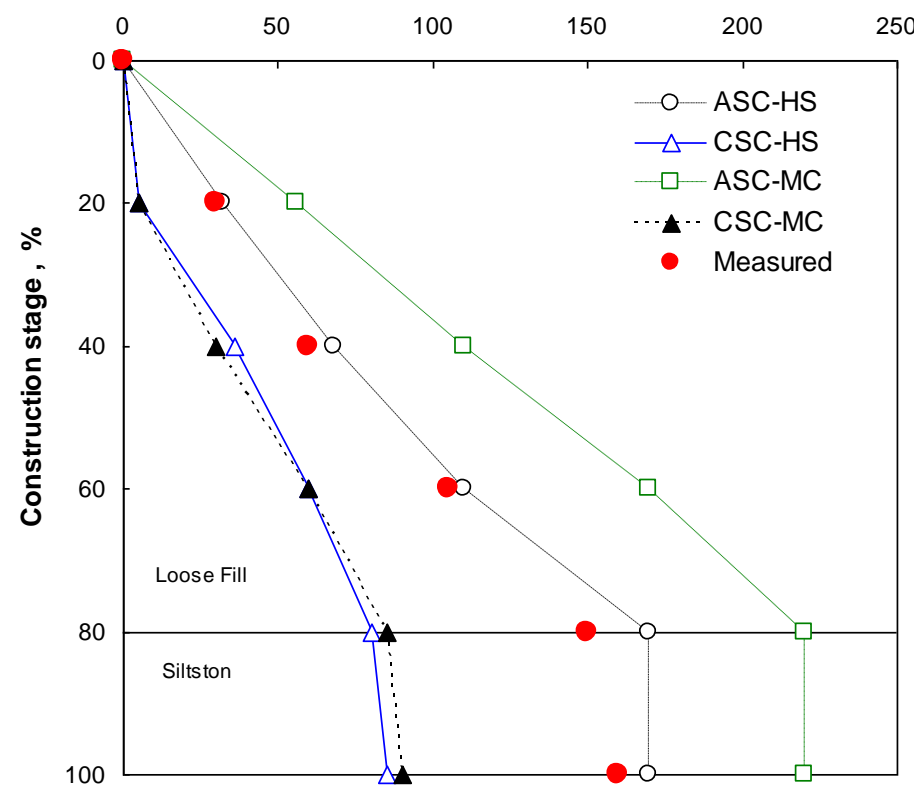

Fig. 8: Maximum lateral wall displacement of soil nail wall with construction stage.

The values of maximum lateral displacement of wall obtained from analyses for both MC-Model and HS-Model by CSC simulation method are almost equal. They are approximately half of the field-measured values. In simulation by ASC method, the values obtained from analysis with HS-Model are very close to the measured values but with MC-Model, the analysis results are larger than measured values significantly.

The reason of difference between lateral wall displacement obtained from ASC and CSC analyses methods is attributed to little modulus of elasticity and collapsibility of loose granular soil. In this type of soil, after excavation of each lift and before installation of nail, significant lateral displacement of wall face is created. The mentioned displacement is taken into account for each stage of construction in ASC method but is neglected in CSC method. 
It is observed from Figure 8 that maximum lateral displacement of soil nail wall do not vary from 80 to $100 \%$ construction stage for all types of analyses. The reason of this observation attributed to beginning of cemented silty sand and sandy siltstone layer. The excavation of this layer do not affect lateral displacement of wall.

\section{Conclusions}

Based on experiences obtained from construction of soil nail wall in loose fill, the results of finite element analyses and field measurements of wall displacements, the following conclusions and recommendations can be made:

1.Soil nailing is an effective and economical method for stabilization of excavations with vertical cut in loose fill ground provided that the sensetive structures to deformation are not placed adjacent to excavation area.

2.For construction of soil nail wall in loose fill, the depth of excavation lift should be limited to $0.8 \mathrm{~m}$ as the excavated face which has the ability to remain unsupported until installation of nail and facing.

3.For correct prediction of soil nail wall displacements by finite element analysis, using actual staged construction (ASC) method with Hardening soil model are recommended. In ASC method excavation and installation of nail and facing elements are simulated in two separate stages.

4.The CSC method is not recommended for analysis of soil nail wall in loose fill.

5.The ASC method with Mohr-Coulomb model is more conservative for prediction of displacement.

\section{References}

[1] FHWA, "Geotechnical Engineering Circular No. 7-Soil Nail Walls," Report No. FHWA 0-IF-03-017., US Department of Transportation, Federal Highway Adminstration, Washigton DC, 2003.

[2] PlAXIS, "Plaxis User's Manual," Delft University of Technology \& Plaxis B.V. the Netherlands, 2006.

[3] V. P. Singh and G. L. S. Babu, "Simulation of Soil Nail Structures Using Plaxis 2D," Plaxis Bulltein, Spring Issue, 2009.

[4] S. S. Liew and C. M. Khoo, "Soil Nail Stabilization for a 14.5 m Deep Excavation at Uncontrolled Fill Ground," in Proceedings of $10^{\text {th }}$ International Conference on Piling and Deep Foundations, Amsterdam, The Netherlands, pp. 165-172, 2006.

[5] S. S. Liew, "Soil Nailing for Slope Strengthening," Geotechnical Engineering, IEM, Malaysia, 2005.

[6] V. P. Singh and G. L. S. Babu, "2D Numerical Simulation of Soil Nail Walls," Journal of Geotechnical and Geological Engineering, vol. 28, no. 4, pp. 299-309, 2010. 